nary means of observation, and this is supported by many considerations. Often exophthalmic goître is associated with other nervous disorders. Gowers ${ }^{3}$ mentions epilepsy, neuralgia, migraine, and ophthalmoplegia. Savage ${ }^{4}$ has shown that it is often connected with mania, general paralysis of the insane, or melancholia. Bristowe $e^{5}$ has recorded a case of exophthalmic goitre in which there were also present external ophthalmoplegia, hemianæsthesia, epileptic fits, and pyrexia. This patient died, but the necropsy revealed nothing. I have recently seen a case associated with a suicidal tendency, and bearing upon this evidence there is the remarkable series of cases recorded by Dr. Cheadle ${ }^{6}$ as occurring all in one family.

We should naturally expect to find that the part of the brain diseased was the floor of the fourth ventricle, for there, of all parts of the body, are important nerves and nerve-centres so closely grouped that we might suspect a lesion in this situation to be capable of causing such diverse symptoms as exophthalmos, thyroid enlargement, and rapidity and palpitation of the heart. In favour of placing the seat of the disease there is the fact that patients with exophthalmic goitre are particularly liable to die suddenly. A series of cases I published ${ }^{7}$ not long ago shows this; and that minute hæmorrhages in the floor of the fourth ventricle will cause sudden death is proved by a case ${ }^{8}$ (not of exophthalmic goître) which I have recorded. Sattler ${ }^{9}$ is fully of opinion that the origin of the malady is in the medulla, near the origin of the vagus, and points out that probably the lesion is a very slight one, and not always precisely in the same place, for the order in which the symptoms appear is very various, and they are curiously mixed with others. Such a slight lesion, he thinks, might be some vascular alteration, and this is especially probable, as the same symptom varies in intensity from time to time.

Now we come to the direct evidence in support of this view. Filehne ${ }^{10}$ operated upon dogs, and cut the upper and inner part of the restiform bodies on both sides with a fine cataract knife. This generally gave rise to one or two of the three cardinal symptoms of exophthalmic goitre ; the most frequent was the palpitation and rapidity of the heart, the next the exophthalmos, which was not always equal, but this is probably because the restiform bodies were not equally cut. The thyroid enlargement was rarely obtained, but it was sometimes, and one dog presented all the three symptoms. He considers that the exophthalmos is due to the vascular dilatation within the orbit, for the retinal arteries dilated; and when the protrusion of the eye was on one side only, rapid enucleation of it showed that orbit to contain more blood than the other. Also the exophthalmos could not be caused by the action of Müller's muscle, for it occurred even if the cervical sympathetic were cut.

Naumann ${ }^{11}$ has recorded a case in which, at the necropsy, the basilar artery was found to be brittle and atheromatous, so that the blood-supply of the medulla might very well have been interfered with, but he gives no histological description. The changes in the brain described by Geigel ${ }^{12}$ were clearly those common in general paralysis, which his patient probably had ; so mine, I think, is the first case on record showing definite local changes in the medulla oblongata, and they are in exactly the position in which they might be suspected to be, for we have seen there are strong reasons for placing the seat of the disease in the floor of the fourth ventricle, and exophthalmic goitre has been attributed to a lesion of the restiform bodies, which were implicated in my case.

No doubt the malady had lasted a long while, and the hæmorrhages were only recent, but I can see no inherent improbability in supposing that a diseased part, even if the lesion is not visible to our means of examination, should be particularly liable to hæmorrhage ; for we know that, as a general rule, diseased structures are more prone to hæmorrhage than healthy ones. In connection with this we must remember that Sattler has good reason for thinking the lesion is a vascular alteration, which would usually disappear after doath. My interpretation of this case is

3 Diseases of the Nervous System, vol. ii, p. 814.

4 Guy's Hospital Reports, vol. xli, p. 31 .

6 St, George's

St. George's Hosp. Rep., 1874.

T. JOURNAL, July 24th, i 886 .
8 Path. Trans., vol. xxiii.

- Graefe und Saemisch, Handbuch der Augenheilkunde, Bd. vi.

10 Communicated to the Physikalisch-Medicinischen Societät zu Erlangen, Sitzung vom 14 Juli, 1879.

12 “ Die Basedow'schen Krankeit," Wirzirburg Med. Wochenschr., vii, S. 70. that the exophthalmic goitre was due to changes in certain parts of the floor of the fourth ventricle, which ordinarily escape detection, because they are so fine. We know that in fevers-and this woman had pneumonia-minute bæmorrhages in the brain are particularly liable to take place shortly before death. They occurred in this case in the floor of the fourth ventricle: for, being diseased, it was the weakest part of the brain, and thus we have had revealed to us the seat of a disease that has hitherto evaded discovery. I have, like many others, constantly seen capillary hæmorrhages which took place in the brain shortly before death, especially in fevers, but I never saw anything in the medulla at: all comparable to the condition we had here. The punctiform hæmor.hages were visible to the naked eye, and markedly discoloured the floor of the fourth ventricle. No one present at the necropsy had ever seen them so evident in the medulla. Considering it is probable that this is the seat of the disease in exophthalmic goitre, it is difficult to believe that the incidence of the hæmorrhages here is the result of chance.

In my article in the JodRNAL in 1886, I called attention to the frequent enlargement of the lymphatic structures in the intestine in exophthalmic goitre. I have since seen it two or three times; it was present to a slight degree in this case, and it is interesting in this connection to note that the patient had diarrhoa.

\section{A CASE OF CHOREA.} FOLLOWED BX

\section{ERYTHEMA ANI ACUTE RHEUMATISM ; WITH REMARKS. ${ }^{1}$}

\author{
By SIR PETER EADE, M.D., F.R.C.P., \\ Consulting Physician to the Norfolk and Norwich Hospital.
}

D. G., aged 17, was admitted into the Norfolk and Norwich Hospital, under my care, on May 26th, 1888, suffering from an attack of acute chorea. He was reported to have been a healthy young man, and never previously to have suffered from either chorea or rheumatism. The heart was unaffected; the urine was 1030, acid, and free from albumen; and the chorea was uncomplicated. Its cause was not apparent, but he appeared to be of nervous temperament. There was no rheumatic taint in his family. The twitching involved more or less the muscles of all the limbs and of the face. The tongue was protruded with a jerk. The intellectual power was decidedly diminished, and the attack was manifestly both general and severe. The temperature was normal. He was now treated with 5 minims of liq. arsenicalis three times daily, but he did not improve; indeed, the symptoms, if anything, got worse, whilst he distinctly lost mental power, the nurse reporting to me that she did not consider that he was altogether in a sane or competent state of mind.

Up to June 11th the temperature continued to be either normal or only at times raised one degree; but on this day it suddenly rose to $102.2^{\circ}$. Simultaneously a bright red erythematous rash appeared in broad patches upon the shoulders, chest, wrists, and knees; whilst the twitching of the face and tongue became more severe. There was scarcely any redness of the throat. He was now ordered a mixture containing dilute sulphuric acid and sulphate of magnesia, with a dose of chloral and bromide of potassium at night. On the evening of this day, and by the following morning, some swelling of the knees and ankles had shown itself.

Next day, June 14th, he complained of pain in the præcordial region. There was increased action of the heart, and a murmur, apparently pericardial, was audible. Temperature $104^{\circ}$; some delirium, more marked at night. The choreic movements still severe, both in face and limbs.

June 16th. A distinct systolic murmur audible, and also unquestionable friction sounds all over the cardiac area. Temperature $103.5^{\circ}$. Joints still swelled and painful. No severe sweatings. Erythematous rash fading. Nocturnal delirium increased, and feebleness of mind a marked symptom. Pulse 130. To take

1 Abstract of paper read before the Norwich Medico-Chirurgical Society. 
15 grains of salicylate of soda. with 7 minims of liquor cinchonæ, every four hours, and a blister to be applied to the præcordia.

June 17th to 25th. The temperature fluctuated considerably. The patient, although more rational, was often very excitable, and (the nurse said) quite irresponsible for his actions. He frequently passed urine into the bed, and occasionally his stools involuntarily or uncontrolled. Choreic movements and joint cheumatism lessened.

On June 30th, as the temperature was then $102^{\circ}$, he was ordered to take also 5 grains of antipyrin night and morning.

On July 2nd, there were reported loud and increased peri- and endo-cardial sounds, with tumultuous action of the heart, but there was little pain here or in the joints. Temperature $101^{\circ}$. Ordered three leeches to be applied to the heart region.

July 4 th. Was greatly and immediately relieved by the leeches, which bled well. The temperature to-day is normal, the heart's action less violent, and the abnormal sounds much diminished in intensity.

After this the temperature remained normal, the rheumatism of the joints disappeared, the chores ceased, and he quickly recovered mental power and intelligence. The rapidity, too, with which the heart murmurs disappeared was very remarkable, so that on July 17th, when he was discharged to go to the Lowestoft Convalescent Home, there was little that was abnormal to be heard or felt in the præcordial region.

This case appears to present several features worthy of a moment's further consideration. The young man was admitted in a state of acute chorea of recent standing, and he remained in this state, apparently without any complications, for several days; then suddenly there was a rise of temperature from normal to $102^{\circ}$, and coincidently there appeared on the skin an eruption of mixed squamous and papular erythema, followed immediately by rheumatic pain and swelling of the joints, and after a little further time by heart complication. The choreic jactitations did not, however, suddenly subside, and there was no ground for considering the question of any metastasis (as it is called) of his disease. In fact, at one period acute chorea, a bright red erythematous eruption, and some swelled and painful joints were all present at the same time. The movements, however, did soon get much less in the lower extremities, which were more particularly affected with the rheumatism.

What is the connection between chorea, erythema, and acute Theumatism? It is well known that chorea and rheumatism have some family relationship. It is also well known that erythema and rheumatism are occasionally seen together, especially that corm of it called erythema nodosum.

But what is their explanation? Chorea is described as an emotional disease, commonly induced by fright or other mental impression, and always to be found classed under the heading of "nervous diseases." Erythema, on the other hand, is differently described and formulated-as, for example, by the late Dr. Tilbury Fox, as a superficial inflammation of the skin, with very slight constitutional symptoms; and Dr. Liveing says: "Erythematous inflammation of the skin is characterised by hyperæmia, which cisappears under pressure, and swelling which is due to serous exudation and migration of a large number of leucocytes into the cutis and subcutaneous tissue."

Of rheumatism, Dr. Bristowe says, this term is used of "inflammatory affections of the joints and other fibrous tissues." Dr. Bruce $^{2}$ says it is "an acute febrile disease, caused by certain obscure climatic and diathetic influences; and characterised by pyrexia, sweats, and acute shifting inflammation of the joints and other structures."

Neither erythema nor rheumatism are restricted to the first two decades of life, or are materially influenced by sex, as chorea is.

These are some of the marked and striking differences between these diseases. Except that they occur in some connection or rela tion to each other, the analogies are not at all striking. The high specific gravity of the urine in both chorea and rheumatism, as specially noted by Dr. Todd, is worthy of mention; and the interrelation of the choreic and rheumaticdiatheses is very remarkable. But it must not be forgotten that even these co-occur in not more than about one-third of the total cases. This frequency of cooccurrence is stated at nearly the same average by many observers. Trousseau and See give the proportion as about onethird of all their cases. Dr. Sturges ${ }^{3}$ says, in 100 cases of chorea,

2 Quain's Dictionary.

3 Lancet, vol. ii, 1888 .
30 per cent., reducible to 25 by exclusions, had rheumatism. The report of the Collective Investigation Committee gives 26 per cent.: whilst Dr. Osler, of Philadelphia (quoted by Dr. Sturges), gives only 15 per cent. Dr. Sturges sums up by saying: "From an extensive survey of statistics, it would seem that 25 per cent., or one-quarter, expresses, as nearly as can be reached, the proportion of rheumatic children who get chorea." He adds that "the claim to kindred with rheumatism, which is made on the part of chorea, is not reciprocated. Thus in Dr. Whipham's analysis ${ }^{4}$ of 655 cases of rheumatism, chorea preceded in only 13 , or less than 2 per cent."

Trousseau does not give any figures as to the order of occurrence of these two affections. He only says that chorea rarely precedes the rheumatism, whilst it often follows it. This case of mine is one of the rare examples in which the chorea showed itself firstin fact, was present for many days before the secondary affections presented themselves.

Once again, erythema is noted as occasionally occurring in connection with rheumatism, but the variety of it so occurring, though occasionally erythema simplex, is usually that termed erythems nodosum. In this case the erythema is distinctly the $E$ squamosum and papulatum. Trousseau speaks of 128 collected cases of chorea, in seventy of which febrile complications existed. Rheumatic fever was present twenty-five times, and exanthematous ferers seventeen times. He does not mention erythema in this list, neither do I find this disease alluded to by him as an accompaniment of chorea, or allied or related to it.

Although obscure and difficult of determination, yet necessarily there is some common bond of connection between these three disorders, either chemical, neurotic, or bacterial, and it is one of the problems of the future to discover what this may be, and what is the explanation of the morbific cause producing its effect sometimes singly, sometimes in two, and sometimes in all three of these combinations in one and the same human body.

What can it be that can produce in the same individual simultaneously such an emotional, eruptive, and articular disease?

The immediate causes which have been assigned for chorea are emotion, fright, nervous exhaustion, general debility, and cerebral embolism. For rheumatism: paralytic chill, excess of lactic acid, micrococci, or other vegetable germs in the blood, malaria. For erythema : digestive or medicinal irritation of the intestinal mucous membranes, organic poisons in the blood. But Hebra honestly confesses that we are in a state of " complete ignorance as to the cause of these erythemata."

Perhaps, on the whole, it is most likely that some organic bloodcause will be found hereafter to be the efficient inducer of these various conditions, or so-called different diseases. We know that the presence of micrococci or germs in the blood is already considered by some to afford the best explanation of the rheumatic phenomena ; and in connection with this idea it is already proved that new growths are present in the pulmonary organs in pneumonis - a disesse induced by almost identical external influences as rheumatic fever-whilst there is a strong suspicion that germ life may be intimately connected with the valvular exudations of endocarditis. We know, also, that erythema is often produced by organic blood-poisons, such as that of variola, cholera, or typhoid fever; and if the efficient cause of chorea should be proved to be minute cerebral embolisms, as thought probable by Dr. Hughlings Jackson and others, it is by no means impossible that germ-bearing blood may be the cause of the capillary obstructions.

It is true, a very strong argument in opposition to the view of these diseases being due to such organic causes may be urged in the fact that none of the three are communicable or epidemic. But although the fact of contagiousness or communicability evidences the existence of an organic because reproducible cause, yet the absence of this in the present state of our knowledge scarcely proves the contrary, especially as we cannot exclude the possibility of the products of the germ-life being the (chemical) cause of disease, rather than the presence of the germs themselves, whether this product be lactic acid or of the class termed ptomaines.

Some other points in connection with this case are well worthy of brief notice did time permit, thus:

1. The erythema which ran its usual course, and faded away after four or five days, just as if uncomplicated.

2. The very excited action of the heart which followed the appearance of the joint rheumatism. This action was violent and - Report of Collective Investigation Committee, 1888. 
excessive, but it was noticeable that it scarcely produced the respiratory or general distress which might have been expected. There was apparently endocardial valvular murmur, as well as loud exo-cardial friction sound, but it is remarkable how entirely all valvular murmur disappeared on the remission of the other heart symptoms. It is probable, I think, that in this case a portion (or possibly the whole) of this valvular murmur may have been due to the irregular choreic contractions of the muscle of the heart-a cause which is fully recognised and understood, and which was fully illustrated by a case of fatal chorea which I reported to this Society some few years ago, in which an apex murmur had during life been both rough and loud and constant, and had been diagnosed as being due to lymph exudation, but in which, on post-mortem examination, all the valves were found to be perfectly healthy.

3. It is further to be noticed, as to the treatment of the case, that the arsenic given at first failed to produce any of its usual good effect upon the chorea, and that both the erythema and rheumatism appeared during the time of its exhibition. After a time the existence of the chorea was ignored, and the rheumatic trouble was treated in the ordinary way with 15-grain doses of salicylate of soda (guarded with a little cinchona) taken every four hours. On June 30th, as both the rheumatism and the shorea were subsiding, but the temperature remained too high, a 5-grain dose of antipyrin was also given night and morning with some benefit; and two days later, as the pericardial friction and excited heart action continued, three leeches were applied to the præcordial region, and allowed to bleed freely into a warm poultice. The effect of these leeches was marked and immediate; the temperature in two days had fallen to normal, the violent palpitation had greatly diminished, and the friction sounds were rapidly disappearing.

From this time all the symptoms quickly improved; indeed, the rapidity of improvement was most striking, and in about a fortnight the young man appeared to be quite well. The chorea had ceased, the mind had recovered its rationality, and both the eruptive and rheumatic symptoms had quite disappeared. I may mention that this rapid recovery from chorea and its complications has been noticed by authors as one of the peculiar features of the disease.

I have thus indicated a few, and a few only, of the more interesting salient points with which this curious compound case bristles. If it serves no other purpose, it serves to illustrate how many are the unsolved problems of even the more common diseases with which we have to deal-problems which may well occupy the thoughtful and inquiring minds of the members of this Society.

\section{ABSTRACTS OF THE MILROY LECTURES}

\author{
ov
}

\section{OCCUPATIONS AND TRADES IN RELATION TO PUBLIC HEALTH.}

\section{Delivered before the Royal College of Physicians of London, March, 1889.}

Bx JOHN T. ARLIDGE, M.D. AND B.A.LOND.,

Fellow of the College: Physician to the North Staffordshire Infirmary, etc.

\section{LECTURE III.}

\section{MINOR INDUSTRIES}

IIorsehair.-In continuing his description of the dusts produced by animal substances, the lecturer said that though clean horsehair was harmless, some of the foreign hair imported was in a filthy state. During the process of unpacking, sorting, and cleaning by combing and carding this dirty horsehair, an offensive dust arises. Anthrax had been produced in the persons engaged in this trade: Thackrah, in 1831, had noticed that the employment

1 See especially a report by Dr. James Russell, medical officer of health Glasgow, in the Eighth Report of the Medical Officer to the Local Government Glasgow, in the Eighth Report of the Medical Officer to the Local Government
Board, 1878-79. Hair from infected districts has since this date been rejected, and Dr. Russell informed Dr. Arlidge that no cases have occurred in the Glasgow factory since that report was made. was dangerous, though without recognising that the symptoms were those of anthrax. ${ }^{2}$

Horn, Bone, Ivory, Mother of Pearl.-The dust arising from the manufacture of horn had but little injurious effect, but that from bone and ivory was more noxious, and might produce respiratory trouble. In cleaning and dressing feathers a dust was given off which caused a sense of suffocation and cough; the workers generally wore a piece of some textile material across the mouth to protect them. The trade was very limited. The dust given off in the manufacture of mother-of-pearl resembled that given off from limestone, both chemically and in its effects. The artisans engaged in the pearl button trade were anxious to maintain a monopoly, and their association had adopted a by-law forbidding the introduction of improved processes; they preferred a short life with high wages. The earliest symptom observed in motherof-pearl workers was dyspncea; later on cough commenced; the lesions found after death were pronounced. ${ }^{3}$

Vegetable Dusts: Cotton.

The examination of industrial diseases attributable to the inhalation of dust of vegetable origin is, the lecturer continued, our next topic. Such dust arises from cotton, linen, jute, cocoa-nut fibre, esparto, and other grasses used in paper making, from flour and gutta-percha, and from wood. To this list may also be added dust arising from rags used in papermaking and for other purposes.

Sorting, Scutching, Carding, etc.-Cotton, when removed from the pods, is in a condition much nearer to that required for the after-processes than flax when gathered. It arrives in bales, in which it has been packed by hydraulic pressure. Hence the first process is to open out the fibres, and to sort the contents of sereral bales in order to obtain an average staple. It has next to be cleansed from seeds and other foreign matters. This is effected by repeated acts of combing and driving off the dust, a work accomplished by scutching or blowing, willying, and other machines. By their operation a thin ribbon or rope-like product, called the " sliver," is presently obtained, having all its fibres laid in one direction, and freed from accidental foreign particles as well as from short and broken fibres. Such, in brief, omitting minor operations, are the stages through which cotton passes previously to its being spun into yarn, and prior to its being woven into cloth or calico. The larger portion of the labour in cotton mills is carried out by females; it involves long standing, but otherwise no strong physical exertion. Scutching and carding are very dusty operations, but the evils therefrom are obviated by the use of enclosed machines. This simple expedient has greatly lessened the amount of disease formerly existing among carders.

Stripping and Grinding.--One accessory proceeding productive of dust still survives called "stripping." It is necessitated by the entanglement and clogging of the teeth of the machines with broken fibres and other matters, and consists in the removal of these by manual effort. Further, the teeth get blunted, and, at intervals, require sharpening, the business of workmen called " grinders." Happily, the necessity for both these operations has, of late years, been greatly reduced by inventions directed to making the machines automatic or self-stripping, and to improving the construction of the combs to save sharpening.

Quality of Cotton.-The dust generated by carding is greater where inferior cotton is worked, as its staple is shorter and brittle. The advantages of a superior quality are felt not only in the early preparatory stages, but also when it reaches the spinning machines, where its greater strength of fibre renders less "piecing' needful. On reaching the weaving department the yarn falls to the hands of winders and warpers, and in the next place is sized and placed on the weaving frames.

Spinning and Weaving.-Excepting some kinds of spinning and the business of weaving, the processes concerned in making cotton, after the preparatory stages are past, present few features of an unhealthy character, other than long hours, long standing, and confinement in the close and often heated air of rooms. In the spinning rooms, however, where " high numbers" are spun, there is both dust and an elevated, unhealthy, moist atmosphere. In the weaving sheds, matters are very much worse,

2 In the eighteenth century the occurrence of the disease among persons who handled skins, bristles, horns, and hoofs of infected cattle (fellmongers, furriers, fur dyers, mattressmakers, coarse hatmakers, tallow melters) had been recognised by French and Italian physicians.

3 See description of specimen shown to Pathological Society ly Dr. Greenhow in 1870 , Trans., vol. xxi, p. 66 . 